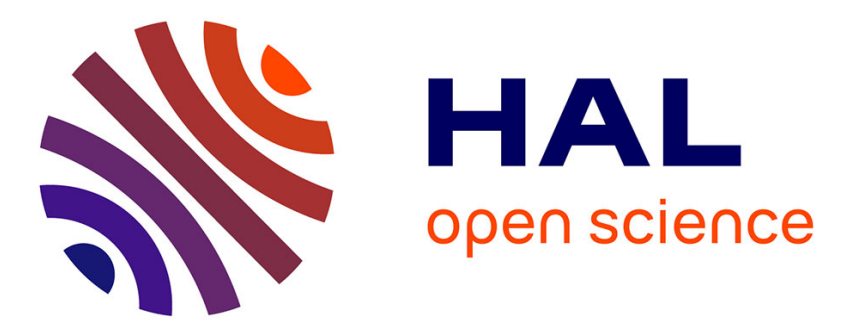

\title{
MEK1/2 Overactivation Can Promote Growth Arrest by Mediating ERK1/2-Dependent Phosphorylation of p70S6K
}

Jean-Philippe Guégan, Frédéric Ezan, Luc Gailhouste, Sophie Langouët, Georges Baffet

\section{To cite this version:}

Jean-Philippe Guégan, Frédéric Ezan, Luc Gailhouste, Sophie Langouët, Georges Baffet. MEK1/2 Overactivation Can Promote Growth Arrest by Mediating ERK1/2-Dependent Phosphorylation of p70S6K. Journal of Cellular Physiology, 2014, 229 (7), pp.903-915. 10.1002/jcp.24521 . hal01061238

\section{HAL Id: hal-01061238 \\ https://hal.science/hal-01061238}

Submitted on 5 Sep 2014

HAL is a multi-disciplinary open access archive for the deposit and dissemination of scientific research documents, whether they are published or not. The documents may come from teaching and research institutions in France or abroad, or from public or private research centers.
L'archive ouverte pluridisciplinaire HAL, est destinée au dépôt et à la diffusion de documents scientifiques de niveau recherche, publiés ou non, émanant des établissements d'enseignement et de recherche français ou étrangers, des laboratoires publics ou privés. 


\title{
Original Research Article
}

\section{MEK1/2 Overactivation can Promote Growth Arrest by Mediating ERK1/2- Dependent Phosphorylation of p70S6K $+\dagger$}

\author{
Jean-Philippe Guégan1, Frédéric Ezan1, Luc Gailhouste1,2, Sophie Langouët1 †*, and Georges \\ Baffet1 $\uparrow *$
}

1 From Inserm U1085, Institut de Recherche sur la Santé l'Environnement et le Travail IRSET, Université de Rennes 1, Biosit, F-35043 Rennes, France

${ }_{2}$ Present address: Division of Molecular and Cellular Medicine, National Cancer Center Research

Institute,Tokyo, Japan

*Running title: $p 70 S 6 K$ and MAPK-induced growth arrest

$\dagger$ These authors contributed equally to this work.

*To whom correspondence should be addressed: Sophie Langouët and Georges Baffet, IRSET, Université de Rennes 1, Campus de Villejean, CS 34317, 35043 Rennes, France. Tel: (33)2.23.23.45.92. E-mail: sophie.langouet@inserm.fr; georges.baffet@inserm.fr

Keywords: MAPK, ERK, hepatocellular carcinoma, proliferation, cell cycle

Abbreviations: DMSO, dimethyl sulfoxide; ERK, extracellular signal-regulated kinase; MAPK, mitogenactivated protein kinase; MEK, MAPK/ERK kinase; mTOR : mammalian target of rapamycin; MTT, 3(4,5-Dimethylthiazol-2-yl)-2,5- diphenyltetrazolium bromide; p70S6K : 70-kDa S6 kinase; p90 RSK : p90 ribosomal S6 kinase ; RNAi, RNA interference; shRNA, small hairpin RNA

Contract grant sponsors: Institut National de la Santé et de la Recherche Médicale (Inserm), Université de Rennes 1, Ligue contre le cancer du Grand Ouest and by the Association pour la Recherche contre le Cancer (ARC); JP.G. is a recipient of a fellowship from the Ministère de l'Enseignement Supérieur et de la Recherche and from the Fondation ARC. Contract grant number: Inserm U1085; Fondation ARC DOC $\mathrm{n}^{\circ} 20120604652$

${ }_{t \dagger}$ This article has been accepted for publication and undergone full peer review but has not been through the copyediting, typesetting, pagination and proofreading process, which may lead to differences between this version and the Version of Record. Please cite this article as doi: [10.1002/jcp.24521] 


\begin{abstract}
The extracellular signal-regulated kinase (ERK)1/2 mitogen-activated protein (MAP) kinase pathway has been involved in the positive and negative regulation of cell proliferation. Upon mitogen stimulation, ERK1/ERK2 activation is necessary for G1- to S-phase progression whereas when hyperactived, this pathway could elicit cell cycle arrest. The mechanisms involved are not fully elucidated but a kinaseindependent function of ERK1/2 has been evidenced in the MAPK-induced growth arrest. Here, we show that p70S6K, a central regulator of protein biosynthesis, is essential for the cell cycle arrest induced by overactivation of ERK1/2. Indeed, whereas MEK1 silencing inhibits cell cycle progression, we demonstrate that active mutant form of MEK1 or MEK2 triggers a G1 phase arrest by stimulating an activation of p70S6K by ERK1/2 kinases. Silencing of ERK1/2 activity by shRNA efficiently suppresses p70S6K phosphorylation on Thr421/Ser424 and S6 phosphorylation on Ser240/244 as well as p21 expression, but these effects can be partially reversed by the expression of kinase-dead mutant form of ERK1 or ERK2. In addition, we demonstrate that the kinase p70S6K modulates neither the p21 gene transcription nor the stability of the protein but enhances the translation of the p21 mRNA. In conclusion, our data emphasizes the importance of the translational regulation of $\mathrm{p} 21$ by the MEK1/2-ERK1/2-p70S6K pathway to negatively control the cell cycle progression.
\end{abstract}




\section{INTRODUCTION}

Within the MAPK (Mitogen-Activated Protein Kinase) superfamily, the Raf/MEK/ERK pathway plays a pivotal role in the regulation of numerous physiological processes ranging from proliferation to cell motility, differentiation and cell survival (Shaul and Seger, 2007). In recent years, various mechanisms have been proposed in order to explain the signal specificity of MEK/ERK responses. These include the regulation of signal duration and intensity, the kinase subcellular localization and cross-talks with other signaling pathways (Murphy and Blenis, 2006). The existence of different components at each level of the pathway could also participate in the signal specificity (Wortzel and Seger, 2011). Human cells express three different Raf isoforms (A-Raf, B-Raf and C-Raf), three MEK (MEK1, MEK2, MEK1b) and three ERK isoforms (ERK1, ERK2, ERK1c). While specific functions have been assigned to MEK1b and ERK1c in Golgi fragmentation and mitotic progression (Shaul et al., 2009), ERK1/ERK2 or MEK1/MEK2 isoforms have been considered for a long time as fully redundant proteins because of their high sequence homology and substantially equivalent spatiotemporal regulations.

However, these kinases could also perform specific functions in specific contexts. For instance, ERK2 but not ERK1 could regulate the EMT transition of MCF10A cells or the 3D migration of MDA-MB-231 breast cancer cells (Shin et al., 2010; von Thun et al., 2012). In contrast, ERK1 but not ERK2, appeared to be the main regulator of normal or transformed hepatocyte survival (Fremin et al., 2012; Guegan et al., 2013). Nevertheless, the notion of functional specificity between these isoforms remains controversial. As demonstrated in the proliferation of fibroblasts, the apparent specificities could only be a simple reflection of the predominant expression of one isoform over the other (Lefloch et al., 2007; Voisin et al., 2010). Given its implications in the regulation of cell survival and proliferation, pro-oncogenic functions of the MEK/ERK pathway have been demonstrated both in vitro and in vivo (Kim and Choi, 2010; Malumbres and Barbacid, 2003). Aberrant activation of this pathway, resulting from the expression of active mutants of Ras, Raf or MEK1/2, induced the in vitro transformation of fibroblasts or epithelial cells (Brunet et al., 1994; Cowley et al., 1994; Voisin et al., 2008) as well as the hypertrophy of different tissues in vivo (Bueno et al., 2000; Scholl et al., 2004). Paradoxically, sustained activation of the Ras/Raf/MEK/ERK pathway can also induce senescence and/or growth arrest in different normal cells such as primary fibroblasts, T-cells or hepatocytes (Chen et al., 1999; Serrano et al., 1997; Sewing et al., 1997; Tombes et al., 1998). This growth arrest can also be found in different tumor cell lines, generally derived from tumors where Ras/Raf mutations are rare, like glioma, prostate carcinoma, medullary thyroid carcinoma, small cell lung carcinoma or rhabdomyosarcoma (Ciccarelli et al., 2005; Hong et al., 2009; Ravi et al., 1998). This antagonistic control of the cell cycle by the ERK pathway has been postulated to represent an important tumorigenesis barrier whose physiological importance has been demonstrated in vivo by the observation of cellular senescence in pre-malignant lesions (Collado et al., 2005; Michaloglou et al., 2005). Heretofore, various intermediate pathways have been shown to participate in the Ras/Raf-induced growth arrest, like p38/PRAK, Wnt or JAK/STAT pathways (Park et al., 2003; Sun et al., 2007; Ye et al., 2007). However, our knowledge of the molecular mechanisms specifically regulated by the MEK/ERK kinases remains quite limited. And yet, a precise characterization of this key mechanism against tumorigenesis could be useful to elicit the development of new therapeutic strategies to suppress tumor growth. The MEK/ERK-induced growth arrest has been associated with the expression of various cell cycle regulators such as induction of the $\mathrm{p} 53$ tumor suppressor or different cell cycle inhibitors like p27 KIP1,p21wAF1 or p16inK4a (Lin et al., 1998; Ravi et al., 1998; Zhu et al., 1998). Whereas their involvements are dependent on the cellular context, the expression of p21WAF1 seems to be a more general event and has been found in p53-dependent and independent mechanisms (Lee et al., 1999; Olsen et al., 2002; Sewing et al., 1997; Woods et al., 1997). ERK1/2 kinases could increase p21 expression by regulating different transcription factors such as Sp1, Ets1/2 or C/EBP $\alpha-\beta$ (Park et al., 2000; Vaque et al., 2005). Whereas this role required a kinase function of ERK, a non-catalytic function of the proteins was recently highlighted in the regulation of p 21 expression. However, the mechanisms by which ERK inactive mutants induces growth arrest have not been elucidated (Hong et al., 2009).

In this study, we aimed to elucidate the mechanisms involved in the MEK/ERK-induced growth arrest. As a model, we used the Huh-7 cell line derived from a human hepatocellular carcinoma, a malignancy where Ras/Raf mutations are rare. By performing transient expression of active forms of MEK1 or MEK2, we showed that aberrant activation of the MEK/ERK pathway induced a G1-phase arrest. We demonstrated that ERK1 and ERK2 both stimulated the expression of p21 in a redundant and non-catalytic manner by stimulating the phosphorylation of p70S6K on Thr421/Ser424 and the subsequently cap-dependent translation of $\mathrm{p} 21$. This model has been proved in both liver and breast cancer cells. 


\section{MATERIALS AND METHODS}

Cell culture and reagents- The human hepatocellular carcinoma cell lines Huh-7D12 and HepG2, as well as the human breast cancer cells MCF-7, were maintained in DMEM $4.5 \mathrm{~g} / \mathrm{L}$ glucose supplemented with $10 \%$ FCS, penicillin $(20 \mathrm{UI} / \mathrm{ml})$ and streptomycin $(20 \mu \mathrm{g} / \mathrm{ml})$. 3-(4,5-Dimethylthiazol-2-yl)-2,5diphenyltetrazolium bromide (MTT), cyclosporine A, cycloheximide and the PDK1 inhibitor GSK2334470 (GSK) were from Sigma Aldrich (St Quentin Fallavier, France). The inhibitors GF109203X (GFX) and Wortmannin were from Calbiochem (VWR, Fontenay-sous-Bois, France). The inhibitor Rapamycin and the antibodies raised against P-Akt, P-ERK1/2 (Thr202/ Tyr204), P-JNK, p21, P-p38, P-p70S6K (Thr389), Pp70S6K (Thr421/ Ser424), p70S6K , P-S6 (Ser240/244), P-4E-BP1 (Ser65), 4E-BP1, mTOR, cyclin D1, cyclin E2, cyclin A2, cyclin B1, p27, p53 and P-p90 RSK were purchased from Cell Signaling (Ozyme, Saint-Quentin-en-Yveline, France). The antibody anti-human Rb (clone G99-2005) was from BD bioscience (Le Pont de Claix, France). Polyclonal antibodies against ERK1 (sc-94), ERK2 (sc-154), HA (sc-805), MEK1 (sc-219), MEK2 (sc-524), p16 (sc1661),c-Myc (sc-40) and Hsc- 70 (sc-7298) were from Santa Cruz Biotechnology (Heidelberg, Germany). Secondary antibodies conjugated to horseradish peroxidase were obtained from Dako (Trappes, France).

Transfection and RNA interference experiments- Small hairpin RNAs (shRNA) targeting human MEK1, MEK2, ERK1, ERK2, P70S6K and mTOR as well as scramble sequence were provided by the company Transat (Lyon, France). Sequences were vector-inserted into the pRetro-SUPER plasmid expressing the puromycin resistance gene (Screeninc, Amsterdam, Netherlands). DNA Plasmids pCMV HA-MEK1 wild type (MEK1-WT), K97A (MEK1-K) and S218D/S222D (MEK1-DD), pCMV HA-MEK2 wild type (MEK2-WT), K101A (MEK2-K) and S222D/S226D (MEK2-DD) and the plasmid His-p21 were kindly provided by Dr. Sylvain Meloche (Institute for Research in Immunology and Cancer, Montréal, Canada). MEK1- DD and MEK2-DD are constitutively active and MEK1-K and MEK2-K are the dominant negative forms of MEK1/2. The plasmids pCMV-ERK1 K71R and pCMV-ERK2 K52R, the dominant-negative forms, were nicely provided by Dr. Peter Shaw (University of Nottingham, UK). DNA transfections were carried out using XtremeGene 9 DNA transfection reagent (Roche, Meylan, France) according to the manufacturer's instructions. Briefly, cells were plated in a $35 \mathrm{~mm}$-petri dish. After an overnight incubation, $2 \mu \mathrm{g}$ of shRNA plasmid (carrying puromycin resistance gene) or pBABE-puro vector $+1 \mu \mathrm{g}$ of expression plasmid were mixed with $5 \mu \mathrm{l}$ of XtremeGene 9 DNA (Roche) and then added to the cells. For transient transfections, cells were selected during $24 \mathrm{~h}$ by puromycin $(4.5 \mu \mathrm{g} / \mathrm{ml})$ and cyclosporine $(5 \mu \mathrm{M})$ as described (Lefloch et al., 2007). For stable cell line generation, transfected cells were selected during 1 month with puromycin $(2 \mu \mathrm{g} / \mathrm{ml})$ and cultured under selection pressure as described (Guegan et al., 2013).

Proliferation assays- To measure proliferation, 2500 cells were seeded in 96-well plate. At indicated time, cell number was determined using colorimetric MTT assay. Briefly, cells were incubated with $0.5 \mathrm{mg} / \mathrm{ml}$ of MTT for $2 \mathrm{~h}$ at $37^{\circ} \mathrm{C}$ and formazan cristals were dissolved in DMSO. Absorbance was measured at $550 \mathrm{~nm}$ on Spectramax microplate reader (Molecular Devices, Wokingham, UK). Background absorbance at 690 $\mathrm{nm}$ was subtracted. A proliferation index was then calculated as the absorbance ratio of cells at indicated time to absorbance at day 1 , and expressed as relative units (RU). Proliferation inhibition was calculated using the formula (1- ((proliferation index of cells) / (proliferation index of control cells))) and expressed as percentage.

Reverse transcriptase and polymerase chain reactions- Total RNAs were extracted from Huh-7 cells using the kit NucleoSpin RNA II (Macherey-Nagel, Hoerd, France). Concentrations of total RNA were measured on NanoDrop ND-100 (NanoDrop Technologies, Wilmington, DE) and $1 \mu \mathrm{g}$ of RNA was subjected to a reverse transcription reaction using the High Capacity cDNA Reverse Transcription kit from Applied Biosystems (Foster City, CA). Real-time quantitative polymerase chain reaction (qPCR) was performed using SYBR Green PCR Master Mix (Applied Biosystems) on the ABI Prism 7700 Sequence Detector System (Applied Biosystems). All reactions were conducted according to manufacturer's instructions. Fold inductions of p21 mRNA were calculated according to the 2- $\Delta \Delta \mathrm{ct}$ method. Primer sequences were as follows: CDKN1A 5'-CTGGAGACTCTCAGGGT CG-3' (Fwd) and 5'-CGGCGTTTGGAGTGGTA GA3' (Rev); 18S RNA 5'- CGGCTACCACATCC AAGGAA-3' (Fwd) and 5'-GCTGGAATTACCG CGGCT-3' (Rev). 
Immunoblots- To extract total proteins, cells were washed once with phosphate-buffered saline and then lysed in a buffer containing $15 \mathrm{mM}$ p-nitrophenylphosphate, $15 \mathrm{mM} \mathrm{MgCl} 2,25 \mathrm{mM}$ MOPS pH $7.2,15 \mathrm{mM}$ EGTA, $60 \mathrm{mM} \beta$-glycerophosphate, $2 \mathrm{mM}$ DTT, $1 \mathrm{mM}$ orthovanadate, $1 \mathrm{mM} \mathrm{NaF}, 1 \mathrm{mM}$ phenylphosphate, $100 \mathrm{mM}$ benzamidin and $1 \mathrm{X}$ of Complete protease inhibitor cocktail (Roche). $20 \mu \mathrm{g}$ of total cell extract were resolved on 6,5-12\% SDS-PAGE and transferred onto nitrocellulose membrane for $1 \mathrm{~h}$ using a TransBlot TM cell apparatus (Biorad, Marnes-la-coquette, France). Membranes were incubated overnight at $4{ }^{\circ} \mathrm{C}$ with appropriate primary antibody and then with HRP-conjugated secondary antibody for $1 \mathrm{~h}$ at room temperature. Immunoblots were analyzed on the Fujifilm LAS-3000 imager (Fujifilm, Tokyo, Japan). Densitometric analyses were performed on the MultiGauge software (Fujifilm) or on the ImageJ software (National Institutes of Health).

Statistical analysis- Results are expressed as the mean \pm standard deviation (SD). Data were analyzed with two-tailed Student $t$ test. Differences were considered significant when $\mathrm{P}<0.05\left(^{*}\right)$ and $\mathrm{P}<0.01(* *)$. All experiments were performed at least three times. 


\section{RESULTS}

Sustained ERK activity alters Huh-7 cell proliferation- In order to study the involvement of the MEK/ERK pathway in the regulation of Huh-7 cell proliferation, we first transiently expressed different mutant forms of MEK1 or MEK2 and analyzed the proliferative capacity of transfected cells by MTT assay. As shown in Figure 1, differences in Huh-7 proliferation appeared according to the activity of expressed MEK1 or MEK2-WT (wild-type), -K (dominant negative) and - DD (constitutively active). Indeed, wild-type MEK1 or MEK2 expression did not modify the proliferative capacity of the cells or the level of ERK1/2 basal activation. However, when active form of MEK1 or MEK2 was expressed, Huh-7 cells exhibited a sustained activation of ERK1/2 kinases and a reduced proliferation (Figure 1). In those cells, ERK activity was comparable to that obtained after a constant EGF stimulation (Supplementary Figure 1). Moreover, it is to note that no cell death or apoptosis engagement was detected in MEK1/2-DD expressing cells (data not shown). A high ERK activity, mediated by constitutively active form of MEK1 or MEK2, could thus be sufficient to impede the proliferation of human hepatocellular carcinoma cells.

Interestingly, we observed that the dominant negative form of MEK1 slowed down the growth of Huh-7 cells while the inactive form of MEK2 had no impact on it. This is consistent with our previous demonstration, both in vitro and in vivo, that MEK1 was specifically involved in the proliferation of hepatocellular carcinoma cells (Gailhouste et al., 2010). Indeed, as shown in Figure 2A, Huh-7 cells stably knocked-down for MEK1 exhibited a decreased proliferation rate compared to control cells. On the contrary, MEK2 silencing did not alter the growth of Huh-7 cells even if it decreased basal ERK1/2 activation similarly to MEK1. Recently, two different groups have shown that the apparent functional specificity observed between ERK1 and ERK2 in fibroblast proliferation was only due to the predominant expression of ERK2. As a consequence, ERK1 invalidation did not impact on ERK1/2 total activity as ERK2 deletion did and thus had less effects on proliferation (Lefloch et al., 2007; Voisin et al., 2010). Hence, to ascertain that the MEK2 kinase was not involved in Huh-7 cell proliferation, we tried to rescue the phenotype of MEK1-targeted cells by expressing wild-type form of the kinase MEK1 or MEK2. In MEK1 silenced cells, an inhibition of cell proliferation was seen and the proliferation could be rescued by the overexpression of MEK1 in silenced cells (shMEK1+ pMEK1-WT) (Figure 2B). On the contrary, MEK2-WT expression failed to counterbalance the loss of MEK1 despite the high expression of the kinase MEK2 (Figure 2C). In order to ensure that the MEK2 inability to rescue was not caused by an insufficient activity, we tried to restore the proliferation of MEK1 silenced cells by expressing the active form of MEK2 (MEK2-DD). As shown in Figure 2C, expression of constitutively active MEK2 induced a high level of ERK1/2 activity but also failed to rescue the cell proliferation. Unexpectedly, the expression of the active form of MEK1 did not act as an improved version of wild-type MEK1 as the proliferation defect was not rescued anymore. In contrast, MEK1-DD amplified the inhibition of proliferation triggered by the loss of MEK1 (Figure 2B). Hence, all these data indicate that MEK1, but not MEK2, could be specifically required for inducing the proliferation of human transformed hepatocytes. However, an "over" ERK1/2 activity, induced either by the active forms of MEK1 or MEK2, can be sufficient to mediate a growth arrest in human hepatocellular carcinoma cells.

ERK1/2 sustained activity induces $p 21$ expression in a redundant and kinase-independent manner - The Raf/MEK/ERKmediated growth arrest has been shown to be associated with the regulation of various proteins, depending on the cellular context. Thus, we next tried to characterize the mechanisms involved in the proliferation inhibition of Huh-7 cells. As shown in Figure 3A, expression of active form of MEK1 or MEK2 induced a high ERK1/2 activation and resulted in a G1 phase arrest, as observed by the increased level of cyclin D1, the reduced expressions of others cyclins (e.g. Cyclin A2, E and B1) and the unphosphorylated status of the kinase cdc2, which is naturally phosphorylated on Tyr15 in the S- and G2phases of the cell cycle (Norbury et al., 1991). We also noticed that the G1 phase arrest seemed to be dependent on $\mathrm{p} 21 \mathrm{WAFI}$ expression as the expression level of the cell cycle inhibitor was greatly increased in MEK1/2-DD expressing cells, contrarily to p27KIP1, whose level was not altered, or p16INK4A which presented a reduced expression. Moreover, similar induction of p21 was observed in MEK1-silenced cells expressing MEK2-DD (data not shown). This p21 massive expression should be sufficient to inhibit cdk4/6-cyclin $\mathrm{D}$ activities as indicated by the reduced retinoblastoma protein $(\mathrm{Rb})$ phosphorylation (Figure $3 \mathrm{~A})$. However, to ascertain that $\mathrm{p} 21$ persistent expression could regulate the growth of transformed hepatocytes, we next induced an ectopic expression of p21 in Huh-7 cells and analyzed their proliferation. MTT assays revealed that cell growth was greatly impaired by the mere presence of p21wAF1 (Figure 3B). Moreover, p21 over-expression inhibited Huh-7 proliferation to a similar extent as compared to the 
constitutive activation of MEK1 or MEK2 (Figure 3C), which suggested that the growth arrest induced by high MEK/ERK activity could rely on p21 action. As a consequence, we used, in the rest of this study, the expression of p21 as a surrogate marker to analyze the mechanisms implied in MEK/ERK-mediated growth arrest. We next investigated whether the cytostatic signal was mediated specifically or not by ERK1 or ERK2. For this purpose, we transiently silenced by shRNA each of the kinases in cells harboring an active form of MEK1 or MEK2. As shown in Figure 4A, p21 induction by MEK1-DD or MEK2-DD was just slightly decreased by the loss of ERK1 whereas it was completely abolished in cells silenced for ERK2. Consistently, cells knocked-down for ERK2 were less subjected to the antiproliferative effect triggered by MEK1/2-DD over-expression in contrast to shERK1 or control cells (Figure 4B). To test if the growth arrest specifically relied on ERK2, we next inhibited endogenous ERK1 or ERK2 activity by expressing dominant-negative forms of ERK1 (K71R) or ERK2 (K52R) in Huh-7 cells and analyzed the induction of 21 upon MEK activation. In contrast with shRNA-based experiments, the inhibition of ERK1 or ERK2 by the kinase-dead form could not prevent the expression of the cell cycle inhibitor induced by active MEK. Nevertheless, the dominant negative mutants efficiently reduced both basal and induced p90 RSK activation (an ERK1/2 substrate used here as a read-out for in vivo ERK kinase activity) (Figure 4C). Next, we tried to rescue p21 expression in shERK2 cells using the kinase-dead form of ERK1 or ERK2. As shown in Figure 4D, ERK1 K71R as well as ERK2 K52R could both partially restore p21 induction upon MEK activation, while inhibiting endogenous ERK activities. Hence, ERK1 and ERK2 could both inhibit the proliferation of Huh-7 cells by increasing p21 level, in a redundant and kinase independent manner.

p70S6K is required for the growth arrest induced by the MEK/ERK pathway- To get further insight in the mechanisms associated with MEK/ERK-induced growth arrest, we analyzed whether other signaling pathways were modified by MEK1 or MEK2 constitutive activation. In MEK1-DD or MEK2-DD Huh-7 cells, no activation or inhibition of the PI3K-, JNK- and p38 pathways was noticed (Figure 5A). Nevertheless, an important phosphorylation of the kinase p70S6K (70-Kda S6 kinase) could be seen on residues Thr421 and Ser424, what led to a slight increase in the Thr389 phosphorylation. Phosphorylation of its S6 substrate on ser 240/244 was also greatly induced by constitutive activation of MEK1 or MEK2. To test the importance of p70S6K activation during the growth arrest, we compared the phosphorylation status of this kinase in control or in ERK2-silenced cells, which are less prone to the proliferation inhibition (Figure 5B). In those cells, phosphorylations of p70S6K on Thr421/Ser424 and S6 on Ser 240/244 were strikingly reduced. The increased phosphorylation of the Thr389 residue was also lost by the silencing of ERK2. Interestingly, we did not find major modifications in the phosphorylation of the 4E-BP1 protein, another mTOR target, between shCtl or shERK2 cells upon MEK1/2 overactivation. The residues Thr 421 and Ser424 of p70S6K are located in a full consensus site of phosphorylation by the kinases ERK1/2 (e.g. $\mathrm{P}-\mathrm{X}-\mathrm{Ser} / \mathrm{Thr}-\mathrm{X})$. Therefore, we checked whether this phosphorylation was directed by ERK, by expressing the kinase-dead mutant form of ERK1 or ERK2 (Figure 5C). As previously, the dominant negative mutants inhibited endogenous ERK1/2 activities (reduced p-p90 RSK level). However, they failed to prevent Thr421/Ser424 phosphorylation of p70S6K upon MEK1/2 activation. In contrast, their expression was sufficient to restore partially the phosphorylation of p70S6K and S6 in ERK2-silenced cells (Figure 5D). Full activation of the p70S6K protein is dependent on phosphorylations of multiple Thr and Ser residues, which are regulated by successive actions of different kinases, depending on the cell type and stimulus (Fenton and Gout, 2011). The main regulator of p70S6K activity is the complex mTORC1 which includes the proteins mTOR (mammalian Target Of Rapamycin), Raptor and G $\beta$ L (Kim et al., 2003). As ERK1/2 has been shown to activate mTORC1 both directly and indirectly (Carriere et al., 2011; Ma et al., 2005), we then tested the involvement of this complex in MEKinduced p70S6K activation. The chemical inhibition of mTOR by rapamycin did not inhibit the p70S6K phosphorylation on Thr421/Ser424 whereas Thr389 one was totally abolished (Figure 5E). Other proteins and notably the kinases PDK1, Akt and the conventional PKCs have been shown to regulate p70S6K activation (Iijima et al., 2002; Magnuson et al., 2012). However, the phosphorylation of Thr421/Ser424 induced by active mutant of MEK1/2 did not involve those kinases as chemical inhibition of PDK1 by GSK2334470 (GSK), PI3K by wortmannin or PKCs by GF109203X (GFX) did not modify the level of p70S6K phosphorylation (Figure 5E). The kinase mTOR could also act in another complex named mTORC2 (mTOR, Rictor, mLST8) which has been initially described as rapamycin-insensitive (Sarbassov et al., 2004). Thus, in order to test the involvement of this complex, mTOR expression was directly silenced by shRNA in Huh-7 cells. As shown in Figure 5F, the loss of mTOR completely abrogated p70S6K phosphorylation on Thr389, both in control and in MEK1/2DD expressing cells. Nevertheless, phosphorylation on Thr421/Ser424 was not totally impacted by the 
inhibition of mTOR. Hence, these data show that ERK could stimulate p70S6K phosphorylation on Thr421/Ser424, independently of its kinase activity and of the activation of PDK1-, PI3K/Akt/mTOR- and PKC pathways.

To study the requirement of p70S6K in MEK/ERK induced growth arrest, we next knocked-down its expression by shRNA and analyzed the proliferative capacities of cells. RNAi-mediated decrease of p70S6K activity did not strongly modify ERK1/2 activation but it completely prevented the expression of the cell cycle inhibitor p21 induced upon MEK activation (Figure 6A) or upon HGF treatment (Supplementary Figure 2). Consequently, p70S6K-silenced cells were less subjected to the growth arrest induced by active forms of MEK1/2 than control cells (Figure 6B). As p70S6K could act in the regulation of protein synthesis as well as in regulation of gene transcription, we next investigated which steps of p21 induction was dependent on p70S6K activity. By quantitative PCR analysis, we observed that sustained ERK activity enhanced CDKN1A gene transcription. Indeed, a 4 to 6 fold induction of p21 mRNA could be seen in MEK1/2-DD expressing cells and interestingly, this induction persisted and was not altered when p70S6K was transiently silenced (Figure 6C). Hence p70S6K regulated p21 expression at a posttranscriptional level. The cell cycle inhibitor $\mathrm{p} 21$ exhibits a short halflife and thus requires different phosphorylation events to be stabilized (Child and Mann, 2006). We thus investigated whether p70S6K could regulate p21 stability. To induce p21 expression, Huh-7 cells were first treated with sodium butyrate, a HDAC inhibitor, for $24 \mathrm{~h}$ and protein translation was then blocked with cycloheximide for different times. The expression of p21 was finally monitored by western blot. As shown in Figure 6D, neither the expression of active MEK1 nor the silencing of p70S6K modified p21 stability. In all cases, p21 exhibited a half-life of about 45 minutes, suggesting that p70S6K did not regulate p21 at this level. Finally, due to the central position of p70S6K in the regulation of protein biosynthesis, we analyzed if the kinase could regulate $\mathrm{p} 21$ protein translation. For this purpose, we monitored p21 protein accumulation following proteasome inhibition. As p70S6K did not regulate $\mathrm{p} 21$ stability, this accumulation could be seen as a reflection of the protein translation efficiency. In this setting, we observed that the p21 level increases more rapidly in control cells than in Huh-7 cells stably knocked-down for p70S6K (Figure 6E). Interestingly, this slower accumulation seems not to be specific to p21 and it could also be observed with c-Myc oncogene whereas p27 and p53 showed same translation rate in control cells as in p70S6K-silenced cells.

Finally, we wanted to know whether the requirement of p70S6K for the MAPK-mediated growth arrest was restricted to Huh-7 cells or could be observed in other tumor cell lines. As shown in Figure 7, expression of active forms of MEK1/2 triggered p70S6K phosphorylation on Thr421/Ser424 and p21 expression in HepG2 cells, another human hepatocellular carcinoma cell line. Indeed, we noticed that p21 expression was also dependent, in these hepatic cells, on p70S6K activity as silencing of the kinase reduced both basal and induced expression of the cell cycle inhibitor (Figure 7A). Furthermore, we also observed that p70S6K requirement for MAPK-induced growth arrest was not restricted to liver cancer as similar conclusions could be made on the human breast cancer cell line MCF-7 (Figure 7B). 


\section{DISCUSSION}

In the present study, we have shown that aberrant activation of ERK1/2 kinases could impede cellular growth by simultaneously increasing p $21 \mathrm{WAF} 1$ gene transcription and enhancing its protein synthesis via a p70S6K-dependent mechanism. We also demonstrated that the kinases ERK1 and ERK2 could both participate in the MAPK-mediated growth arrest in a redundant manner and independently of their kinase activity.

Functional specificities of MAPKs- With more than $85 \%$ of amino acid homology, the kinases MEK1 and MEK2, as well as ERK1 and ERK2, have been considered for a long time as fully redundant proteins (Shaul and Seger, 2007). However, several studies, including those of our team, have shown that these kinases were not totally interchangeable. First, MEK1 and MEK2 can be differently regulated. Indeed MEK1 can undergo a negative feedback mediated by ERK2 via the phosphorylation of its Thr292 residue, a regulatory site lacking in MEK2 protein (Eblen et al., 2004). Furthermore, MEK1 but not MEK2 can bind to the scaffold protein MP1 (Schaeffer et al., 1998) and can be activated by the A-Raf kinase (Wu et al., 1996), suggesting that different protein affinities could exist. Second, functional differences have been demonstrated in vitro or in vivo following the specific extinction of MEK isoform. For instance, MEK1 gene invalidation in mice is lethal at the embryonic stage unlike MEK2 knock-out, revealing an predominant role for MEK1 in the development of extraembryonic tissues (Belanger et al., 2003; Giroux et al., 1999; Nadeau et al., 2009). Here, we demonstrated an absolute requirement of MEK1 but not MEK2 for the proliferation of hepatocarcinoma cells. MEK1 silencing suppressed the growth of Huh-7 cells and MEK2 overexpression could not compensate for the loss of MEK1. Moreover, expression of a dominant negative form of MEK1, but not MEK2, decreased Huh-7 cell proliferation. Two different studies have convincingly demonstrated that the apparent specificity of the kinases ERK1 and ERK2 in fibroblast proliferation actually reflected their difference of expression (Lefloch et al., 2007; Voisin et al., 2010). For their authors, the specific role of ERK2 seen in the proliferation of many tumor models is related to the higher expression level of ERK2. Therefore ERK2 silencing has a greater impact on ERK total activity than ERK1 extinction and thus will give more severe phenotype. This gene dosage effect could also be found in this study. Indeed, Huh-7 cells express more ERK2 proteins than ERK1, as noticed by western blot using anti-phospho-ERK1/2 antibody. As a consequence, ERK2 silencing, but not ERK1, totally blocked p21 induction and the growth-inhibitory signal upon MEK activation. Nevertheless, kinase-dead form of ERK1 could restore p21 induction in ERK2-silenced cells, demonstrating that ERK1 and ERK2 are both involved in MAPK-induced growth arrest of Huh-7 cells. Same conclusions have been made by Hong et al. in others tumor cell lines (Hong et al., 2009).

Regarding the MEK1/2 functional specificity observed here, we demonstrated that the targeting of MEK1 but not MEK2 inhibited hepatocarcinoma cell proliferation. However in human or mouse tissues, and notably in liver, MEK2 exhibits a higher expression level than MEK1 (Pelech, 2006). Similarly, we observed that MEK2 overexpression could not compensate for the loss of MEK1. Thus MEK1 dependence of Huh-7 cells for proliferation seemed not to be a simple gene dosage effect but instead a specific role of MEK1 may exist in these highly differentiated cells. A specific requirement of MEK1 has also been observed in the proliferation of different cell models (Scholl et al., 2009; Shama et al., 2008; Ussar, 2004). Nevertheless, it is to note that the functional specialization of MEK1 and MEK2 seems to be dependent on cell type since predominant roles of MEK2 over MEK1 have also been underlined in other models (Lee et al., 2011; Voisin et al., 2008). Moreover, MEK1 and MEK2 could have both redundant and specific roles in a same cell type and the notion of functional specificity could thus be dependent on the stimulus type, duration and/or activated signaling cross-talks (Lee et al., 2011).

ERK1/2-dependent phosphorylation of p 70S6K in growth arrest signaling- In this study, we showed that expression of active mutant of MEK1 or MEK2 was sufficient to inhibit the proliferation of human hepatocellular carcinoma cells. By RNAi experiments, we also demonstrated that this growth arrest was linked to the sustained activity of the ERK1/2 kinases and the subsequent induction of cycle inhibitor p21wAF1. Similar results were obtained on normal hepatocytes. Indeed, we have previously shown that the inability of rat hepatocytes to undergo multiple division cycles in primary culture was linked to a ERK2dependent induction of p21 wAF1 (Frémin et al., 2009). Moreover, sustained stimulation of MEK/ERK activities by the cytokine hepatocyte growth factor (HGF) inhibited the in vitro proliferation of different models of human hepatocellular carcinoma (HepG2, Hep3B, Huh-7) and this has also been linked to the induction of p21wAF1 by the MEK/ERK pathway (Shiota et al., 1992; Shirako et al., 2008; Tsukada et al., 
2001). In addition, we showed here that this growth arrest could be mediated by a non-catalytic function of the ERK kinases. Indeed, ERK1/2 kinase-dead mutants could not suppress p21 induction upon MEK activation while blocking endogenous ERK activities (e.g. reduced phospho-p90 RSK level). Moreover, expression of these mutants in ERK2-silenced cells was sufficient to restore p21 induction by active MEK1/2. Even if we cannot totally exclude that the ERK kinase-dead mutants harbored a weak residual activity and did not absolutely demonstrate that the mutants have no activity, these results are consistent with a possible non-catalytic function of ERK as previously described in the MAPK-induced growth arrest (Hong et al., 2009). Moreover, we showed that besides the transcriptional regulation of p21wAF1, the sustained activation of the MEK/ERK pathway could stimulate the translation of the cell cycle inhibitor by allowing the activation of the kinase p70S6K.

The full activation of p70S6K requires phosphorylations of various residues and notably phosphorylations of its Cterminal autoinhibitory pseudosubstrate domain (Ser411, Ser418, Thr421 and Ser424) and different critical sites like Thr389 (Fenton and Gout, 2011). In MEK1/2-DD expressing cells, we noticed an important phosphorylation of the Thr421 and Ser424 sites and only a small increase in the Thr389 phosphorylation. This suggests that the latter phosphorylation seemed to be mediated by a kinase different from ERK1/2. Several kinases have been implicated in the regulation of p70S6K activation. Depending on the cell type, an involvement of PDK1, mTOR, PI3K or PKC kinases was observed (Iijima et al., 2002; Laser et al., 1998; Magnuson et al., 2012). Here, we showed that phosphorylation of Thr421/Ser424 residues was not dependent on these kinases but on ERK1/2 functions, since only ERK2 silencing prevented the phosphorylation of these sites. Nevertheless, we noticed that Thr389 phosphorylation was dependent on a PDK1/PI3K/mTOR pathway. Similarly, it has been shown in neutrophils that the cytokine granulocyte macrophage colony-stimulating factor (GM-CSF) triggered a mTOR-dependent phosphorylation of Thr389 of p70S6K concurrently with a ERK-dependent phosphorylation of Thr421/Ser424. Both phosphorylations were required for full activation of p70S6K kinase (Lehman et al., 2003). ERK-induced phosphorylation of p70S6K on Thr421/Ser424 has also been observed in other models like cardiac muscle cells, epithelial cell or CD8 T-cells (Iijima et al., 2002; Salmond et al., 2009; Zhang et al., 2001). Hence, ERK sustained activation could firmly participate to activate p70S6K, in addition to the $\mathrm{PI} 3 \mathrm{~K} / \mathrm{PDK} 1 / \mathrm{Akt} / \mathrm{mTOR}$ dependent phosphorylation of Thr389.

Nevertheless and despite the fact that Thr421/Ser424 residues are localized in a consensus sequence for ERK phosphorylation (PX[T/S]P), we demonstrated here that ERK-mediated p70S6K activation was regulated by a non-catalytic function of ERK1/2. First ERK deletions by shRNA, but not dominant negative form of ERK, reduced Thr421/Ser424 phosphorylation upon MEK activation. Second, ERK1/2 kinase-dead mutant expression could restore p70S6K phosphorylations on autoinhibitory domains in ERK2-silenced cells. Two different studies have shown that ERK1/2 could interact with p70S6K in cells (Gu et al., 2000; Lehman and Gomez-Cambronero, 2002). Hence, one could speculate that ERK1/2 could act as a scaffold protein to promote the activity of an unknown kinase on p70S6K. Alternatively, the interaction between ERK and p70S6K could mask the C-terminal domain of p70S6K, preventing phosphatase action on Thr421/Ser424.

Finally, we have shown that p70S6K activity was important for MEK1/2-DD-induced growth arrest because its silencing inhibited p21wAF1 expression. We also demonstrated that p70S6K was not required to stimulate CDKN1A gene transcription or to increase p21 protein stability but to enhance the translation of p21 mRNA. Indeed, p21 protein accumulated less efficiently in p70S6K-deficient cells than in control cells, following proteasome inhibition. Due to the short half-life of the protein, the regulation of p21 translation could thus represent an important mechanism to regulate the expression of this cell cycle inhibitor and thus the cellular growth. These results are consistent with the well-defined function of p70S6K in the regulation of protein synthesis (Mamane et al., 2006) and with different studies showing a role of the mTOR/p70S6K pathway in DNA-damage- or mitogen-induced p21 expression (Beuvink et al., 2005; Gaben et al., 2004). Indeed, using rapamycin or its derivate RAD001, those studies have evidenced a role of the mTOR/p70S6K pathway in the control of p21 translation. No modulations of the transcription or of the stability of p21 were seen. However, for one study, the translational regulation was selective to p21 and for the other one, it was a global effect. Here, we noticed that the effect of p70S6K was not selective to p21 as it has also been observed for the protein c-Myc. However, p27 and p53 protein accumulations following proteasome inhibition were not modified by the loss of p70S6K. Given the fact that these latter proteins contain an IRES element, contrarily to p21 (Kannan-Thulasiraman et al., 2008; Miskimins et al., 2001; Ray et al., 2006), we hypothesize that p70S6K could be only required to enhance cap-dependent translation of proteins but further studies will be required to explore this assumption. Moreover, we suggest that in the mTOR/S6K pathway, the kinase p70S6K played a major role in the control of p21 translation as 
we showed that mTOR inhibition did not suppress p21 induction upon MEK activation contrarily to p70S6K targeting.

In conclusion, we have shown that the sustained activation of the kinases ERK1 and ERK2 stimulated p70S6K phosphorylation on Thr421/Ser424 in a redundant and non-catalytic manner and that this activation was required to stimulate cap-dependent translation of the p21 and subsequent growth arrest.

\section{ACKNOWLEDGEMENTS}

The authors thank Transat (Lyon, France) and the "Ligue Nationale Contre le Cancer" for providing human shRNAs. We thank Dr Sylvain Meloche and Dr Peter Shaw for DNA plasmids and Dr Christophe Frémin for the critical reading of this paper.

\section{CONFLICT OF INTEREST}

The authors declare no conflict of interest.

\section{REFERENCES}

Belanger LF, Roy S, Tremblay M, Brott B, Steff AM, Mourad W, Hugo P, Erikson R, Charron J. 2003. Mek2 is dispensable for mouse growth and development. Mol Cell Biol 23(14):4778-4787.

Beuvink I, Boulay A, Fumagalli S, Zilbermann F, Ruetz S, O'Reilly T, Natt F, Hall J, Lane HA, Thomas G. 2005. The mTOR inhibitor RAD001 sensitizes tumor cells to DNA-damaged induced apoptosis through inhibition of p21 translation. Cell 120(6):747-759.

Brunet A, Pages G, Pouyssegur J. 1994. Constitutively active mutants of MAP kinase kinase (MEK1) induce growth factor-relaxation and oncogenicity when expressed in fibroblasts. Oncogene 9(11):3379-3387.

Bueno OF, De Windt LJ, Tymitz KM, Witt SA, Kimball TR, Klevitsky R, Hewett TE, Jones SP, Lefer DJ, Peng CF, Kitsis RN, Molkentin JD. 2000. The MEK1-ERK1/2 signaling pathway promotes compensated cardiac hypertrophy in transgenic mice. The EMBO journal 19(23):6341-6350. Carriere A, Romeo Y, Acosta-Jaquez HA, Moreau J, Bonneil E, Thibault P, Fingar DC, Roux PP. 2011. ERK1/2 phosphorylate Raptor to promote Ras-dependent activation of mTOR complex 1 (mTORC1). J Biol Chem 286(1):567-577.

Chen D, Heath V, O'Garra A, Johnston J, McMahon M. 1999. Sustained activation of the raf-MEK-ERK pathway elicits cytokine unresponsiveness in T cells. J Immunol 163(11):5796-5805.

Child ES, Mann DJ. 2006. The intricacies of p21 phosphorylation: protein/protein interactions, subcellular localization and stability. Cell Cycle 5(12):1313-1319.

Ciccarelli C, Marampon F, Scoglio A, Mauro A, Giacinti C, De Cesaris P, Zani B. 2005. p21WAF1 expression induced by MEK/ERK pathway activation or inhibition correlates with growth arrest, myogenic differentiation and onco-phenotype reversal in rhabdomyosarcoma cells. Molecular Cancer 4(1):41.

Collado M, Gil J, Efeyan A, Guerra C, Schuhmacher AJ, Barradas M, Benguria A, Zaballos A, Flores JM, Barbacid M, Beach D, Serrano M. 2005. Tumour biology: senescence in premalignant tumours. Nature 436(7051):642.

Cowley S, Paterson H, Kemp P, Marshall CJ. 1994. Activation of MAP kinase kinase is necessary and sufficient for PC12 differentiation and for transformation of NIH 3T3 cells. Cell 77(6):841-852.

Eblen ST, Slack-Davis JK, Tarcsafalvi A, Parsons JT, Weber MJ, Catling AD. 2004. Mitogen-Activated Protein Kinase Feedback Phosphorylation Regulates MEK1 Complex Formation and Activation during Cellular Adhesion. Molecular and Cellular Biology 24(6):2308-2317.

Fenton TR, Gout IT. 2011. Functions and regulation of the 70kDa ribosomal S6 kinases. Int J Biochem Cell Biol 43(1):47-59.

Frémin C, Bessard A, Ezan F, Gailhouste L, Régeard M, Le Seyec J, Gilot D, Pagès G, Pouysségur J, Langouët S, Baffet G. 2009. Multiple division cycles and long-term survival of hepatocytes are distinctly regulated by extracellular signal-regulated kinases ERK1 and ERK2. Hepatology 49(3):930-939.

Fremin C, Ezan F, Guegan JP, Gaillouste L, Trotard M, Seyec JL, Theret N, Langouet S, Baffet G. 2012. 
The complexity of ERK1 and ERK2 MAPKs in multiple hepatocyte fate responses. J Cell Physiol 227(1):59-69.

Gaben AM, Saucier C, Bedin M, Barbu V, Mester J. 2004. Rapamycin inhibits cdk4 activation, p 21(WAF1/CIP1) expression and G1-phase progression in transformed mouse fibroblasts. Int J Cancer 108(2):200-206.

Gailhouste L, Ezan F, Bessard A, Fremin C, Rageul J, Langouet S, Baffet G. 2010. RNAi-mediated MEK1 knock-down prevents ERK1/2 activation and abolishes human hepatocarcinoma growth in vitro and in vivo. Int J Cancer 126(6):1367-1377.

Giroux S, Tremblay M, Bernard D, Cardin-Girard JF, Aubry S, Larouche L, Rousseau S, Huot J, Landry J, Jeannotte L, Charron J. 1999. Embryonic death of Mek1-deficient mice reveals a role for this kinase in angiogenesis in the labyrinthine region of the placenta. Current biology : CB 9(7):369372.

Gu M, Lynch J, Brecher P. 2000. Nitric oxide increases p21(Waf1/Cip1) expression by a cGMPdependent pathway that includes activation of extracellular signal-regulated kinase and p70(S6k).

J Biol Chem 275(15):11389-11396.

Guegan JP, Ezan F, Theret N, Langouet S, Baffet G. 2013. MAPK signaling in cisplatin-induced death: predominant role of ERK1 over ERK2 in human hepatocellular carcinoma cells. Carcinogenesis 34(1):38-47.

Hong SK, Yoon S, Moelling C, Arthan D, Park JI. 2009. Noncatalytic Function of ERK1/2 Can Promote Raf/MEK/ERK-mediated Growth Arrest Signaling. Journal of Biological Chemistry 284(48):33006-33018.

Iijima Y, Laser M, Shiraishi H, Willey CD, Sundaravadivel B, Xu L, McDermott PJ, Kuppuswamy D. 2002. c-Raf/MEK/ERK pathway controls protein kinase C-mediated p70S6K activation in adult cardiac muscle cells. J Biol Chem 277(25):23065-23075.

Kannan-Thulasiraman P, Dolniak B, Kaur S, Sassano A, Kalvakolanu DV, Hay N, Platanias LC. 2008. Role of the translational repressor 4E-BP1 in the regulation of $\mathrm{p} 21$ (Waf1/Cip1) expression by retinoids. Biochem Biophys Res Commun 368(4):983-989.

Kim DH, Sarbassov DD, Ali SM, Latek RR, Guntur KV, Erdjument-Bromage H, Tempst P, Sabatini DM. 2003. GbetaL, a positive regulator of the rapamycin-sensitive pathway required for the nutrientsensitive interaction between raptor and mTOR. Mol Cell 11(4):895-904.

Kim EK, Choi EJ. 2010. Pathological roles of MAPK signaling pathways in human diseases. Biochimica et biophysica acta 1802(4):396-405.

Laser M, Kasi VS, Hamawaki M, Cooper Gt, Kerr CM, Kuppuswamy D. 1998. Differential activation of p70 and p85 S6 kinase isoforms during cardiac hypertrophy in the adult mammal. J Biol Chem 273(38):24610-24619.

Lee AW, Nambirajan S, Moffat JG. 1999. CSF-1 activates MAPK-dependent and p53-independent pathways to induce growth arrest of hormone-dependent human breast cancer cells. Oncogene 18(52):7477-7494.

Lee CS, Dykema KJ, Hawkins DM, Cherba DM, Webb CP, Furge KA, Duesbery NS. 2011. MEK2 is sufficient but not necessary for proliferation and anchorage-independent growth of SK-MEL-28 melanoma cells. PLoS One 6(2):e17165.

Lefloch R, Pouyssegur J, Lenormand P. 2007. Single and Combined Silencing of ERK1 and ERK2 Reveals Their Positive Contribution to Growth Signaling Depending on Their Expression Levels. Molecular and Cellular Biology 28(1):511-527.

Lehman JA, Calvo V, Gomez-Cambronero J. 2003. Mechanism of ribosomal p70S6 kinase activation by granulocyte macrophage colony-stimulating factor in neutrophils: cooperation of a MEK-related, THR421/SER424 kinase and a rapamycin-sensitive, m-TOR-related THR389 kinase. J Biol Chem 278(30):28130-28138.

Lehman JA, Gomez-Cambronero J. 2002. Molecular crosstalk between p70S6k and MAPK cell signaling pathways. Biochem Biophys Res Commun 293(1):463-469.

Lin AW, Barradas M, Stone JC, van Aelst L, Serrano M, Lowe SW. 1998. Premature senescence involving p53 and p16 is activated in response to constitutive MEK/MAPK mitogenic signaling. Genes Dev 12(19):3008-3019.

Ma L, Chen Z, Erdjument-Bromage H, Tempst P, Pandolfi PP. 2005. Phosphorylation and functional inactivation of TSC 2 by Erk implications for tuberous sclerosis and cancer pathogenesis. Cell 121(2):179-193.

Magnuson B, Ekim B, Fingar DC. 2012. Regulation and function of ribosomal protein S6 kinase (S6K) 
within mTOR signalling networks. Biochem J 441(1):1-21.

Malumbres M, Barbacid M. 2003. RAS oncogenes: the first 30 years. Nat Rev Cancer 3(6):459-465.

Mamane Y, Petroulakis E, LeBacquer O, Sonenberg N. 2006. mTOR, translation initiation and cancer.

Oncogene 25(48):6416-6422.

Michaloglou C, Vredeveld LC, Soengas MS, Denoyelle C, Kuilman T, van der Horst CM, Majoor DM, Shay JW, Mooi WJ, Peeper DS. 2005. BRAFE600-associated senescence-like cell cycle arrest of human naevi. Nature 436(7051):720-724.

Miskimins WK, Wang G, Hawkinson M, Miskimins R. 2001. Control of cyclin-dependent kinase inhibitor p27 expression by cap-independent translation. Mol Cell Biol 21(15):4960-4967.

Murphy LO, Blenis J. 2006. MAPK signal specificity: the right place at the right time. Trends Biochem Sci 31(5):268-275.

Nadeau V, Guillemette S, Belanger LF, Jacob O, Roy S, Charron J. 2009. Map2k1 and Map2k2 genes contribute to the normal development of syncytiotrophoblasts during placentation. Development 136(8):1363-1374.

Norbury C, Blow J, Nurse P. 1991. Regulatory phosphorylation of the p34cdc2 protein kinase in vertebrates. The EMBO journal 10(11):3321-3329.

Olsen CL, Gardie B, Yaswen P, Stampfer MR. 2002. Raf-1-induced growth arrest in human mammary epithelial cells is p16-independent and is overcome in immortal cells during conversion.

Oncogene 21(41):6328-6339.

Park JI, Strock CJ, Ball DW, Nelkin BD. 2003. The Ras/Raf/MEK/extracellular signal-regulated kinase pathway induces autocrine-paracrine growth inhibition via the leukemia inhibitory

factor/JAK/STAT pathway. Mol Cell Biol 23(2):543-554.

Park JS, Qiao L, Gilfor D, Yang MY, Hylemon PB, Benz C, Darlington G, Firestone G, Fisher PB, Dent P. 2000. A role for both Ets and C/EBP transcription factors and mRNA stabilization in the MAPK-dependent increase in p21 (Cip-1/WAF1/mda6) protein levels in primary hepatocytes. Mol Biol Cell 11(9):2915-2932.

Pelech S. 2006. Dimerization in protein kinase signaling. J Biol 5(5):12.

Ravi RK, Weber E, McMahon M, Williams JR, Baylin S, Mal A, Harter ML, Dillehay LE, Claudio PP, Giordano A, Nelkin BD, Mabry M. 1998. Activated Raf-1 causes growth arrest in human small cell lung cancer cells. J Clin Invest 101(1):153-159.

Ray PS, Grover R, Das S. 2006. Two internal ribosome entry sites mediate the translation of p53 isoforms. EMBO Rep 7(4):404-410.

Salmond RJ, Emery J, Okkenhaug K, Zamoyska R. 2009. MAPK, phosphatidylinositol 3-kinase, and mammalian target of rapamycin pathways converge at the level of ribosomal protein S6 phosphorylation to control metabolic signaling in CD8 T cells. J Immunol 183(11):7388-7397.

Sarbassov DD, Ali SM, Kim DH, Guertin DA, Latek RR, Erdjument-Bromage H, Tempst P, Sabatini DM. 2004. Rictor, a novel binding partner of mTOR, defines a rapamycin-insensitive and raptorindependent pathway that regulates the cytoskeleton. Current biology : CB 14(14):1296-1302.

Schaeffer HJ, Catling AD, Eblen ST, Collier LS, Krauss A, Weber MJ. 1998. MP1: a MEK binding partner that enhances enzymatic activation of the MAP kinase cascade. Science 281(5383):16681671.

Scholl FA, Dumesic PA, Barragan DI, Harada K, Charron J, Khavari PA. 2009. Selective role for Mek1 but not Mek2 in the induction of epidermal neoplasia. Cancer Res 69(9):3772-3778.

Scholl FA, Dumesic PA, Khavari PA. 2004. Mek1 alters epidermal growth and differentiation. Cancer Res 64(17):6035-6040.

Serrano M, Lin AW, McCurrach ME, Beach D, Lowe SW. 1997. Oncogenic ras provokes premature cell senescence associated with accumulation of p53 and p16INK4a. Cell 88(5):593-602.

Sewing A, Wiseman B, Lloyd AC, Land H. 1997. High-intensity Raf signal causes cell cycle arrest mediated by p21Cip1. Mol Cell Biol 17(9):5588-5597.

Shama J, Garcia-Medina R, Pouysségur J, Vial E. 2008. Major contribution of MEK1 to the activation of ERK1/ERK2 and to the growth of LS174T colon carcinoma cells. Biochemical and Biophysical Research Communications 372(4):845-849.

Shaul Y, Seger R. 2007. The MEK/ERK cascade: From signaling specificity to diverse functions. Biochimica et Biophysica Acta (BBA) - Molecular Cell Research 1773(8):1213-1226.

Shaul YD, Gibor G, Plotnikov A, Seger R. 2009. Specific phosphorylation and activation of ERK1c by MEK1b: a unique route in the ERK cascade. Genes Dev 23(15):1779-1790.

Shin S, Dimitri CA, Yoon S-O, Dowdle W, Blenis J. 2010. ERK2 but Not ERK1 Induces Epithelial-to- 
Mesenchymal Transformation via DEF Motif-Dependent Signaling Events. Molecular Cell 38(1):114-127.

Shiota G, Rhoads DB, Wang TC, Nakamura T, Schmidt EV. 1992. Hepatocyte growth factor inhibits growth of hepatocellular carcinoma cells. Proceedings of the National Academy of Sciences of the United States of America 89(1):373-377.

Shirako E, Hirayama N, Tsukada Y, Tanaka T, Kitamura N. 2008. Up-regulation of p21CIP1 expression mediated by ERK-dependent and -independent pathways contributes to hepatocyte growth factorinduced inhibition of HepG2 hepatoma cell proliferation. Journal of cellular biochemistry 104(1):176-188.

Sun P, Yoshizuka N, New L, Moser BA, Li Y, Liao R, Xie C, Chen J, Deng Q, Yamout M, Dong MQ, Frangou CG, Yates JR, 3rd, Wright PE, Han J. 2007. PRAK is essential for ras-induced senescence and tumor suppression. Cell 128(2):295-308.

Tombes RM, Auer KL, Mikkelsen R, Valerie K, Wymann MP, Marshall CJ, McMahon M, Dent P. 1998. The mitogen-activated protein (MAP) kinase cascade can either stimulate or inhibit DNA synthesis in primary cultures of rat hepatocytes depending upon whether its activation is acute/phasic or chronic. Biochem J 330 ( Pt 3):1451-1460.

Tsukada Y, Miyazawa K, Kitamura N. 2001. High intensity ERK signal mediates hepatocyte growth factor-induced proliferation inhibition of the human hepatocellular carcinoma cell line HepG2. J

Biol Chem 276(44):40968-40976.

Ussar S. 2004. MEK1 and MEK2, Different Regulators of the G1/S Transition. Journal of Biological Chemistry 279(42):43861-43869.

Vaque JP, Navascues J, Shiio Y, Laiho M, Ajenjo N, Mauleon I, Matallanas D, Crespo P, Leon J. 2005. Myc antagonizes Ras-mediated growth arrest in leukemia cells through the inhibition of the RasERK-p21Cip1 pathway. J Biol Chem 280(2):1112-1122.

Voisin L, Julien C, Duhamel S, Gopalbhai K, Claveau I, Saba-El-Leil MK, Rodrigue-Gervais I, Gaboury L, Lamarre D, Basik M, Meloche S. 2008. Activation of MEK1 or MEK2 isoform is sufficient to fully transform intestinal epithelial cells and induce the formation of metastatic tumors. BMC Cancer 8(1):337.

Voisin L, Saba-El-Leil MK, Julien C, Fremin C, Meloche S. 2010. Genetic demonstration of a redundant role of extracellular signal-regulated kinase 1 (ERK1) and ERK2 mitogen-activated protein

kinases in promoting fibroblast proliferation. Mol Cell Biol 30(12):2918-2932.

von Thun A, Birtwistle M, Kalna G, Grindlay J, Strachan D, Kolch W, von Kriegsheim A, Norman JC. 2012. ERK2 drives tumour cell migration in three-dimensional microenvironments by suppressing expression of Rab17 and liprin-beta2. J Cell Sci 125(Pt 6):1465-1477.

Woods D, Parry D, Cherwinski H, Bosch E, Lees E, McMahon M. 1997. Raf-induced proliferation or cell cycle arrest is determined by the level of Raf activity with arrest mediated by p21Cip1. Mol Cell

Biol 17(9):5598-5611.

Wortzel I, Seger R. 2011. The ERK Cascade: Distinct Functions within Various Subcellular Organelles. Genes \& cancer 2(3):195-209.

Wu X, Noh SJ, Zhou G, Dixon JE, Guan KL. 1996. Selective activation of MEK1 but not MEK2 by ARaf from epidermal growth factor-stimulated Hela cells. J Biol Chem 271(6):3265-3271.

Ye X, Zerlanko B, Kennedy A, Banumathy G, Zhang R, Adams PD. 2007. Downregulation of Wnt signaling is a trigger for formation of facultative heterochromatin and onset of cell senescence in primary human cells. Mol Cell 27(2):183-196.

Zhang Y, Dong Z, Nomura M, Zhong S, Chen N, Bode AM. 2001. Signal transduction pathways involved in phosphorylation and activation of p70S6K following exposure to UVA irradiation. J Biol Chem 276(24):20913-20923.

Zhu J, Woods D, McMahon M, Bishop JM. 1998. Senescence of human fibroblasts induced by oncogenic Raf. Genes Dev 12(19):2997-3007. 


\section{FIGURE LEGENDS}

FIGURE 1. Constitutive activation of MEK1 or MEK2 inhibits Huh-7 cell proliferation. The proliferation of Huh-7 cells expressing wild-type (WT), kinase-dead (K) or mutant active (DD) form of MEK1 (A) or MEK2 (B) was assessed by MTT assays. Results are expressed as relative units (RU). (C) ERK1/2 activation status was monitored by western blot in Huh-7 cells expressing wild-type or mutant forms of MEK1/2. Data are representative of at least three independent experiments. (Mean $\pm \mathrm{SD}$; * $\mathrm{P}<0.05 ; * * \mathrm{P}<0.01)$

FIGURE 2. MEK1 but not MEK2 is required for cell proliferation. The growth rates of Huh-7 cells stably knocked-down for MEK1 or MEK2 (A) or Huh-7 cells transiently silenced for MEK1 and expressing wild-type (WT) or mutant active (DD) form of MEK1 (B) or MEK2 (C) were assessed by MTT assays (right panels). Results are expressed as relative units (RU). In each case, the efficiency of MEK1 or MEK2 silencing and plasmid expression was monitored by western blot (left panel). Data are representative of at least three independent experiments. (Mean $\pm \mathrm{SD} ; * \mathrm{P}<0.05$;** $\mathrm{P}<0.01$ )

FIGURE 3. Growth arrest induced by the MEK/ERK pathway involves p21 expression. (A) The expression of different cell cycle regulators was analyzed by western blot in Huh-7 cells expressing wildtype (WT), kinase-dead (K) or mutant active (DD) form of MEK1 or MEK2. Expression of MEK1 or MEK2 constructs was verified by immunobloting with anti-HA antibody. (B) Huh-7 were transfected with His-p21 construct and selected by puromycin. The expression of His-tagged p21 was analyzed by western blot (upper panel) and the proliferation rate of selected cells was assessed by MTT assay (lower panel). (C) Comparison of the proliferation rate between Huh-7 cells expressing ectopic p21wAF1, active mutant form (DD) of MEK1 or MEK2 and controls cells. Results are expressed as percent of control cell proliferation. Data are representative of at least three independent experiments. (Mean $\pm \mathrm{SD}$; $* * \mathrm{P}<0.01$ )

FIGURE 4. ERK1 and ERK2 inhibit Huh-7 cells growth in a redundant and non-catalytic manner. (A) Huh-7 were transiently transfected with shRNA targeting ERK1 (shERK1), ERK2 (shERK2) or scramble sequence (shCtl), concomitantly with an active mutant form of MEK1, MEK2 or empty vector. Expression of HA-tagged MEK1 and MEK2 constructs and the induction of the cell cycle inhibitor p21WAF1 was analyzed by western blot. Densitometric analysis were performed to measure p21 induction and results were expressed as relative units (RU) (right panel). (B) The growth arrest induced by active mutant form of MEK1 (pMEK1DD) or MEK2 (pMEK2DD) was evaluated in Huh-7 cells transiently silenced for ERK1, ERK2 or in control cells. Results are expressed as percentage of proliferation inhibition, as described in Materials and Methods section. (C-D) The induction of $\mathrm{p} 21$ by active MEK1/2 was analyzed by western blot in Huh-7 cells expressing kinase-dead mutant form of ERK1 (K71R) or ERK2 (K52R) (C) or transiently silenced for ERK2 and expressing the ERK mutant protein (D). Data are representative of at least three independent experiments (Mean $\pm \mathrm{SD} ; * \mathrm{P}<0.05 ; * * \mathrm{P}<0.01$ ).

FIGURE 5. ERK1/2 sustained signaling promotes p70S6K activation independently of their kinase function. (A) The effects of constitutive activation of MEK1 and MEK2 on various signaling pathways were analyzed in Huh-7 cells by western blot. (B) Huh-7 cells expressing active mutant (DD) form of MEK1/2 or empty vector were transiently silenced or not by shRNA for ERK2 and phosphorylation status of p70S6K was then analyzed by western blot. (C-D) p70S6K activation by active MEK1/2 (MEK1/2DD) was studied by western blot in Huh-7 cells expressing kinase-dead mutant form of ERK1 (K71R) or ERK2 (K52R) (C) or transiently silenced for ERK2 and expressing the ERK mutant protein (D). (E) Huh7 cells expressing active form of MEK1/2 or empty vector were treated for $2 \mathrm{~h}$ with DMSO, GSK2334470 (GSK; $1 \mu \mathrm{M})$, GF109203X (GFX; $2 \mu \mathrm{M})$, Rapamycin $(10 \mathrm{nM})$ or Wortmannin $(500 \mathrm{nM})$. Activation of p70S6K was then analyzed by western blot. (F) Huh-7 cells expressing active mutant form of MEK1/2 or empty vector were transiently silenced by shRNA for mTOR. Phosphorylation status of p70S6K was then analyzed by western blot. For all these experiments, MEK1/2-DD expression was monitored by immunoblotting with anti-HA or anti-P-ERK antibody. Data are representative of at least three independent experiments. 
FIGURE 6. p70S6K is required for the growth arrest induced by the MEK/ERK pathway. Huh-7 expressing active mutant form of MEK1 or MEK2 were transiently transfected with shRNA targeting p70S6K or scramble sequence (shCtl). The induction of the cell cycle inhibitor p21wAF1 was then analyzed by western blot (A) and the growth arrest induced by MEK1/2-DD was assessed by MTT assays (B). Results are expressed as percentage of proliferation inhibition, as described in Materials and Methods section. (C) Total mRNA were submitted to RT-qPCR to determine p21wAF1 expression. Data were normalized relatively to the expression level found in control cells. (D) Huh-7 cells expressing mutant active MEK1 (MEK1-DD) or empty vector were transfected with shCtl or shRNA for p70S6K. Cells were treated for $24 \mathrm{~h}$ with sodium butyrate $(10 \mathrm{mM})$ to induce p21 expression and next with cycloheximide (20 $\mu \mathrm{M})$ for indicated times. Expression of p21 was analyzed by western blot (upper panel) and p21 half-lives were calculated after densitometric analyses (lower panel). As sodium butyrate treatment led to different rate of p21 induction, p21 blot exposition was different between the three conditions. Results are expressed as relative units (RU). (E) Huh-7 stably knocked-down for p70S6K or control cells were treated with MG132 $(10 \mu \mathrm{M})$ for indicated times and accumulation of different proteins were monitored by western blot (left panel). p21, p27 and c-Myc expression were calculated after densitometric analyses and expressed as relative units (RU) (right panel). Data are representative of at least three independent experiments. (Mean $\pm \mathrm{SD} ; * \mathrm{P}<0.05$ ).

FIGURE 7. p70S6K requirement for MAPK-induced growth arrest is not restricted to Huh-7 cells. HepG2 (A) and MCF-7 (B) cells expressing active form of MEK1/2 (MEK1/2-DD) or empty vector were transiently silenced or not by shRNA for p70S6K. p21 expression and p70S6K phosphorylation status were then analyzed by western blot (left panel). p21 expression were calculated by densitometric analyses (right panel) and results expressed as relative units (RU). Data are representative of at least three independent experiments. (Mean $\pm \mathrm{SD} ; * \mathrm{P}<0.05 ; * * \mathrm{P}<0.01$ ). 
Figure 1
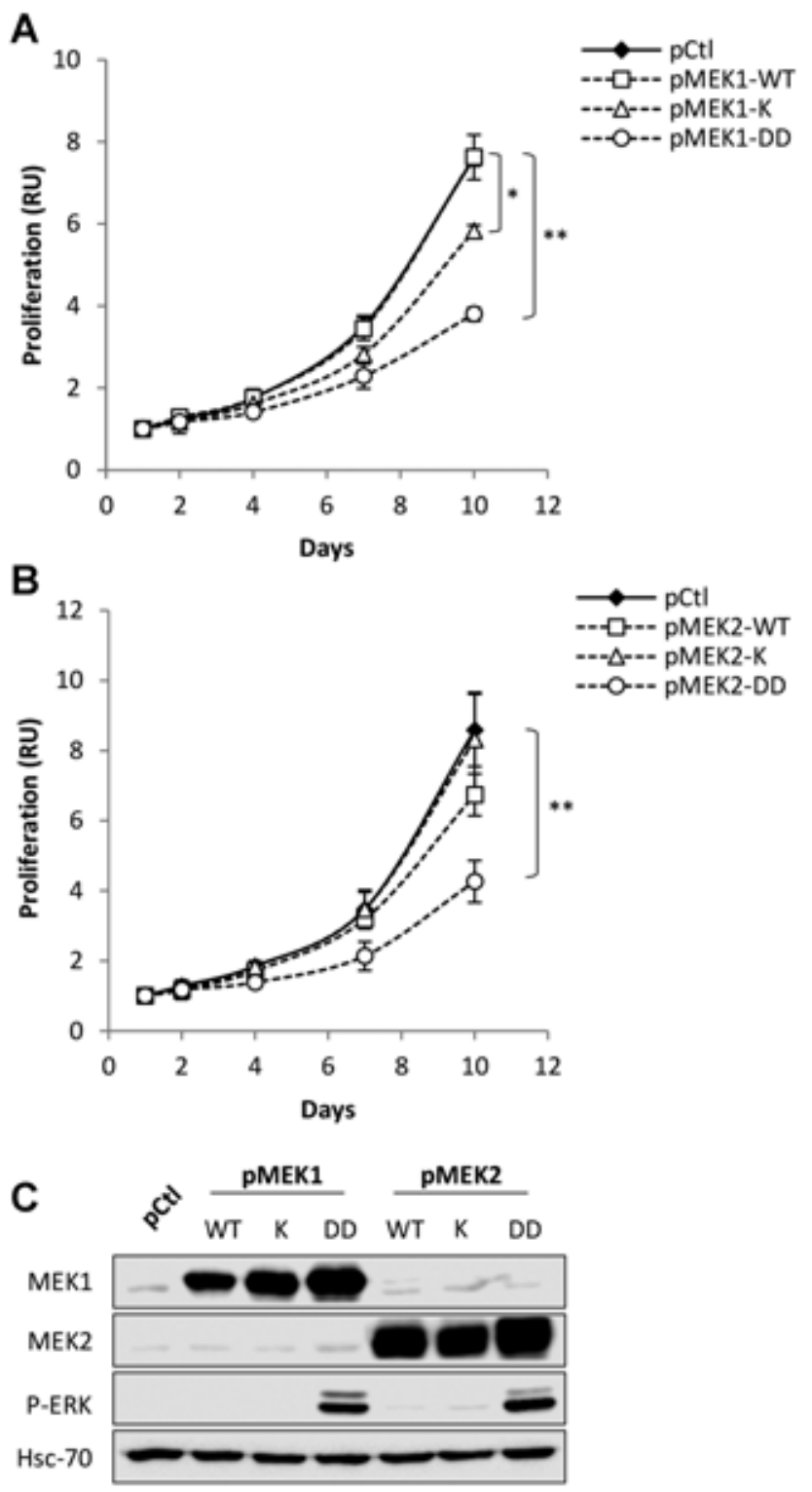
Figure 2

A

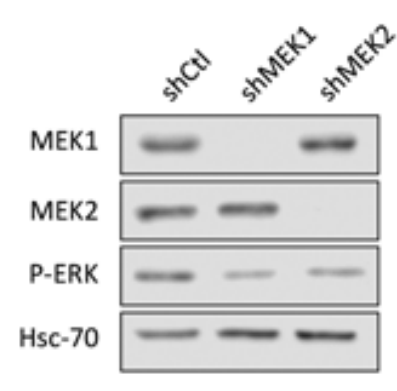

B

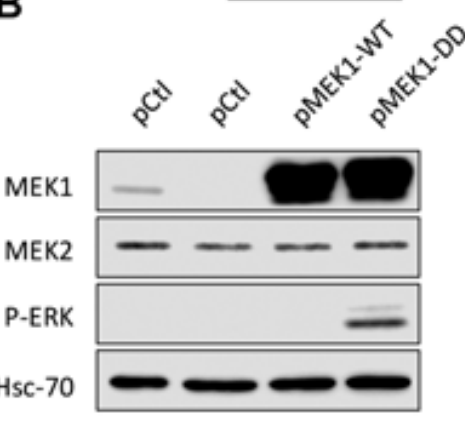

C

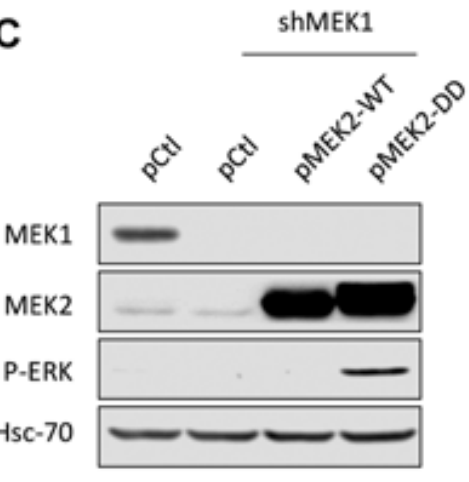

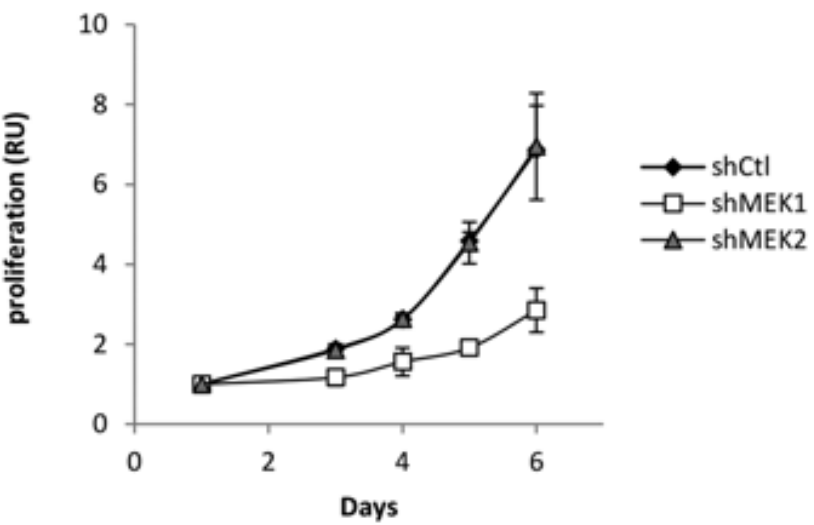
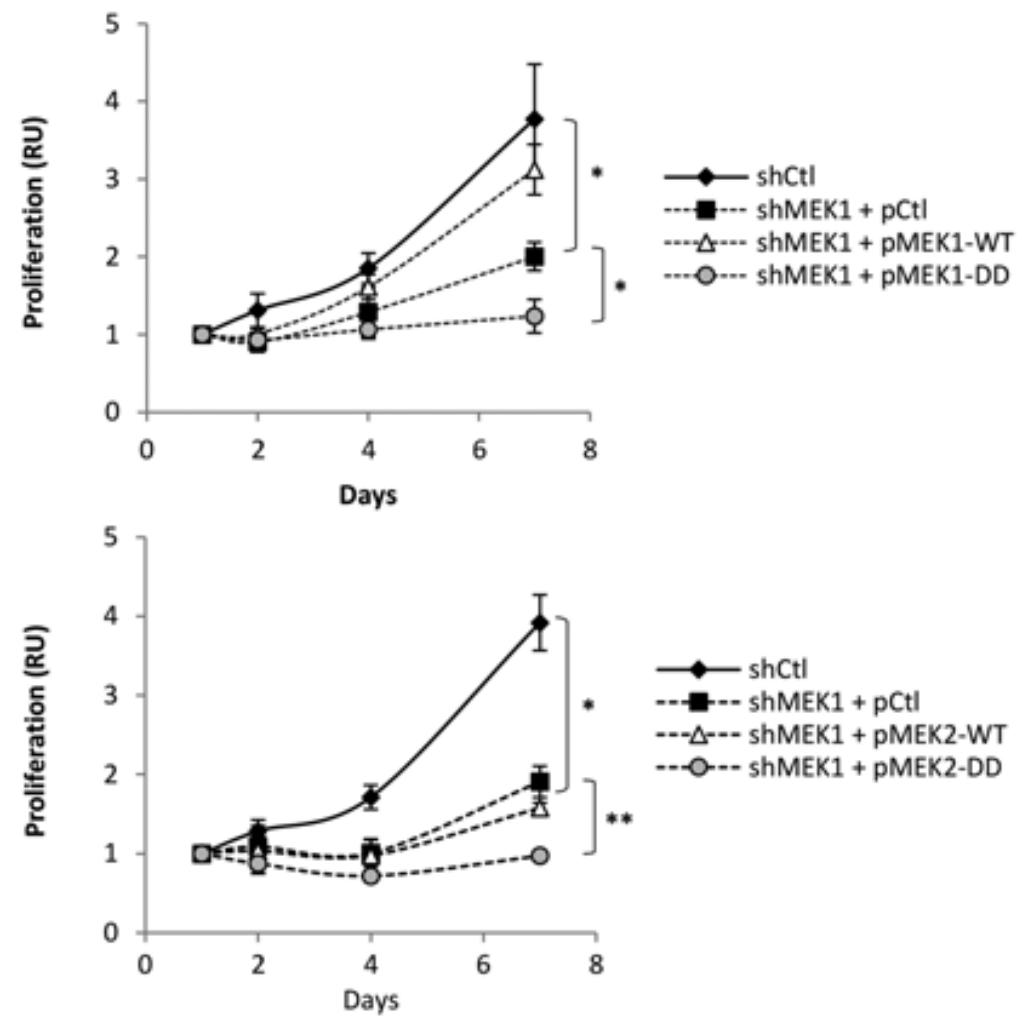
Figure 3

A

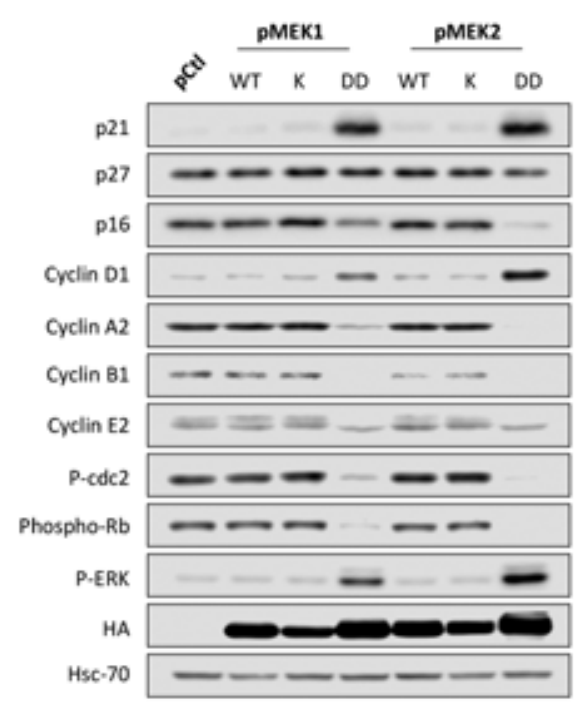

B
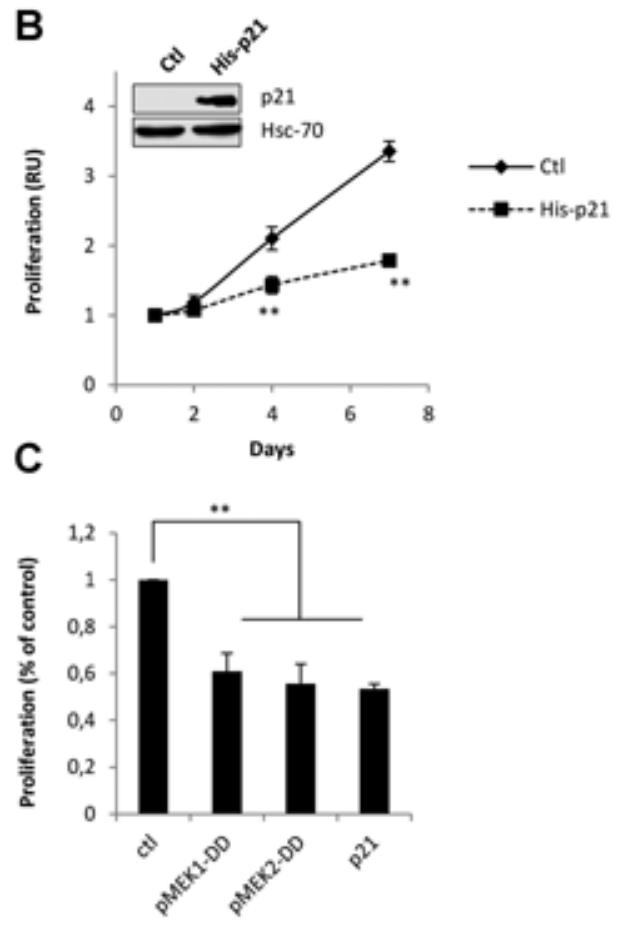
Figure 4
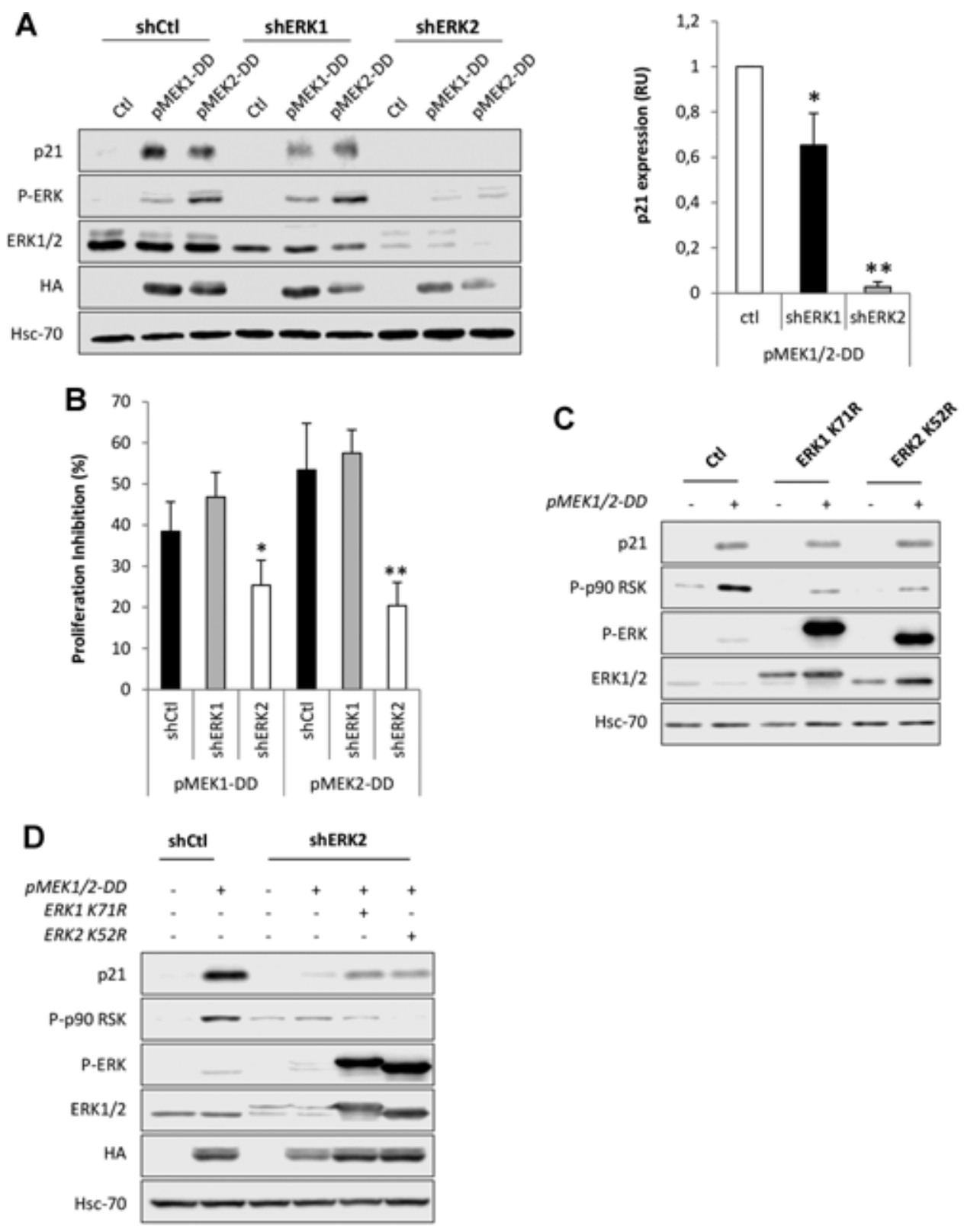


\section{Figure 5}

A

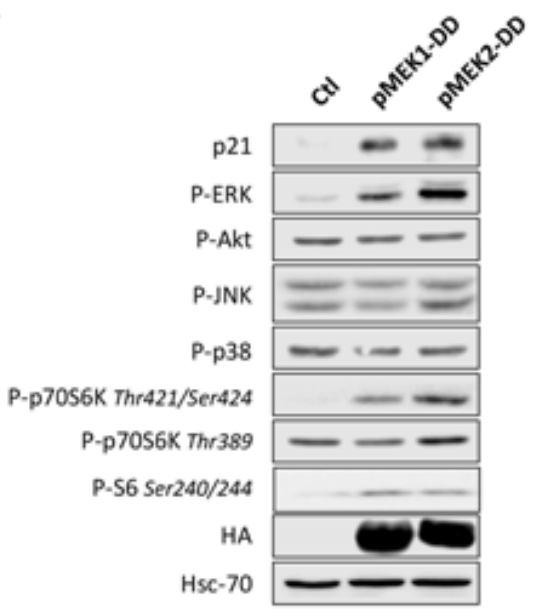

C

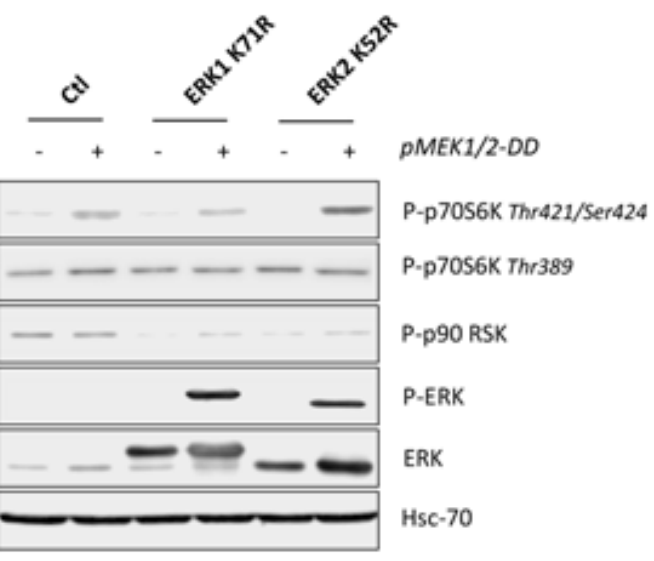

E

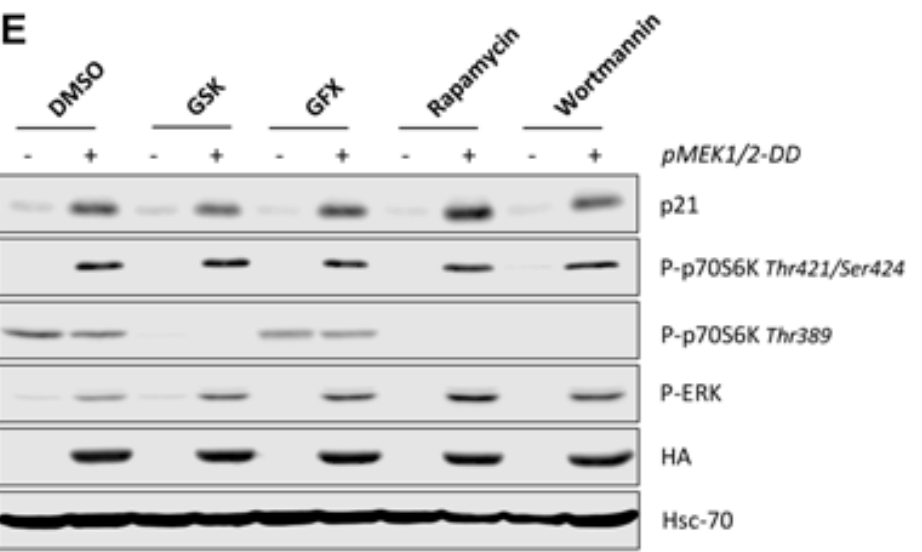

B

P-p7056K Thr421/Ser424

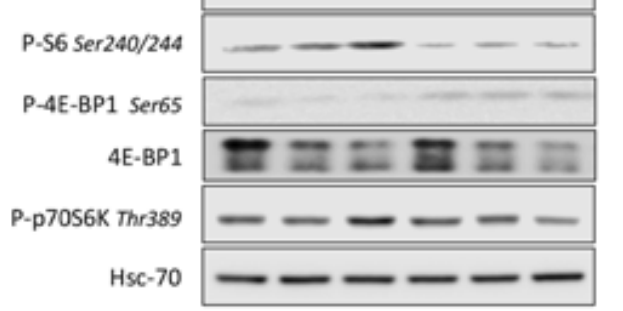

D

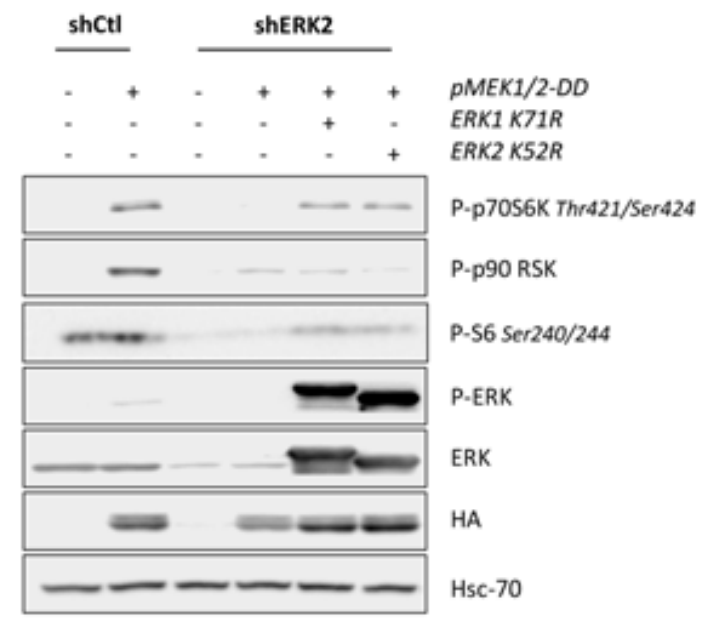

F

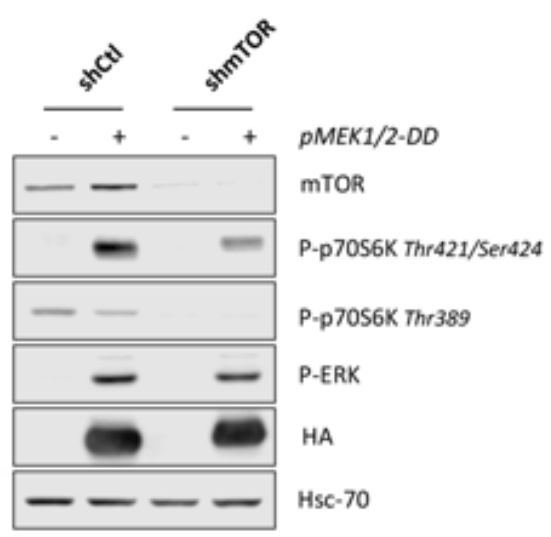


Figure 6

A

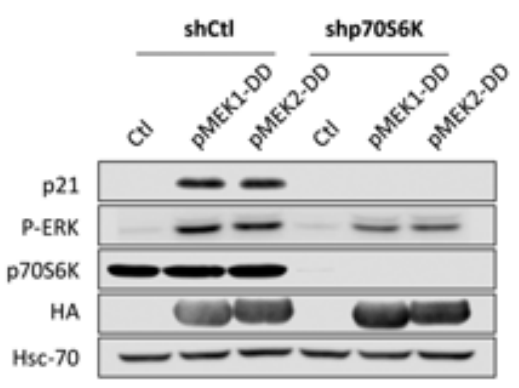

C

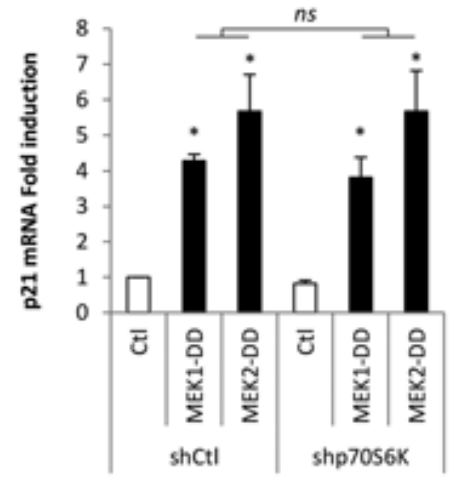

B
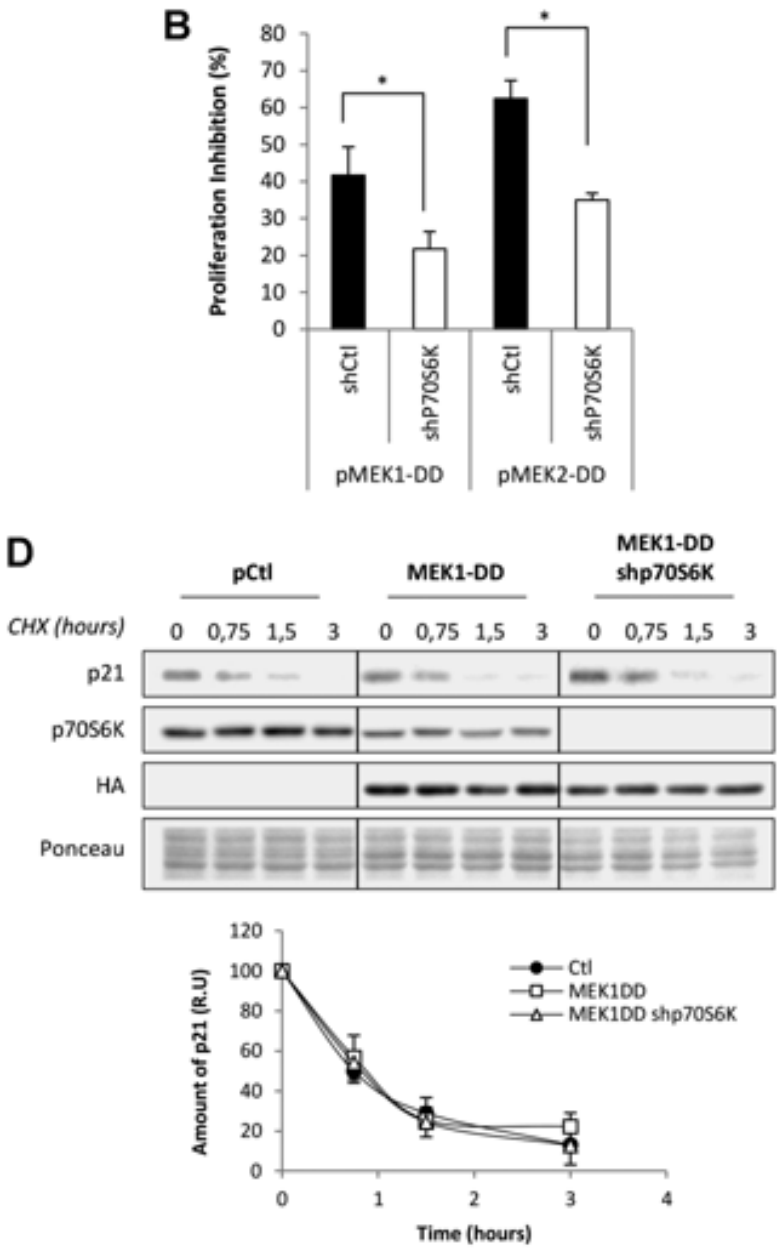
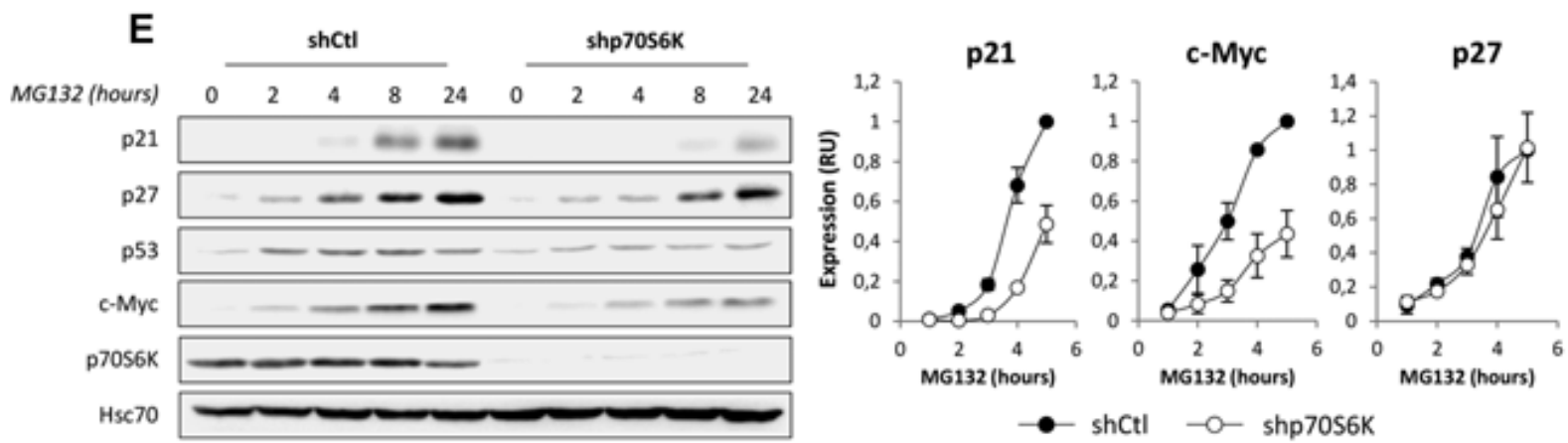
Figure 7
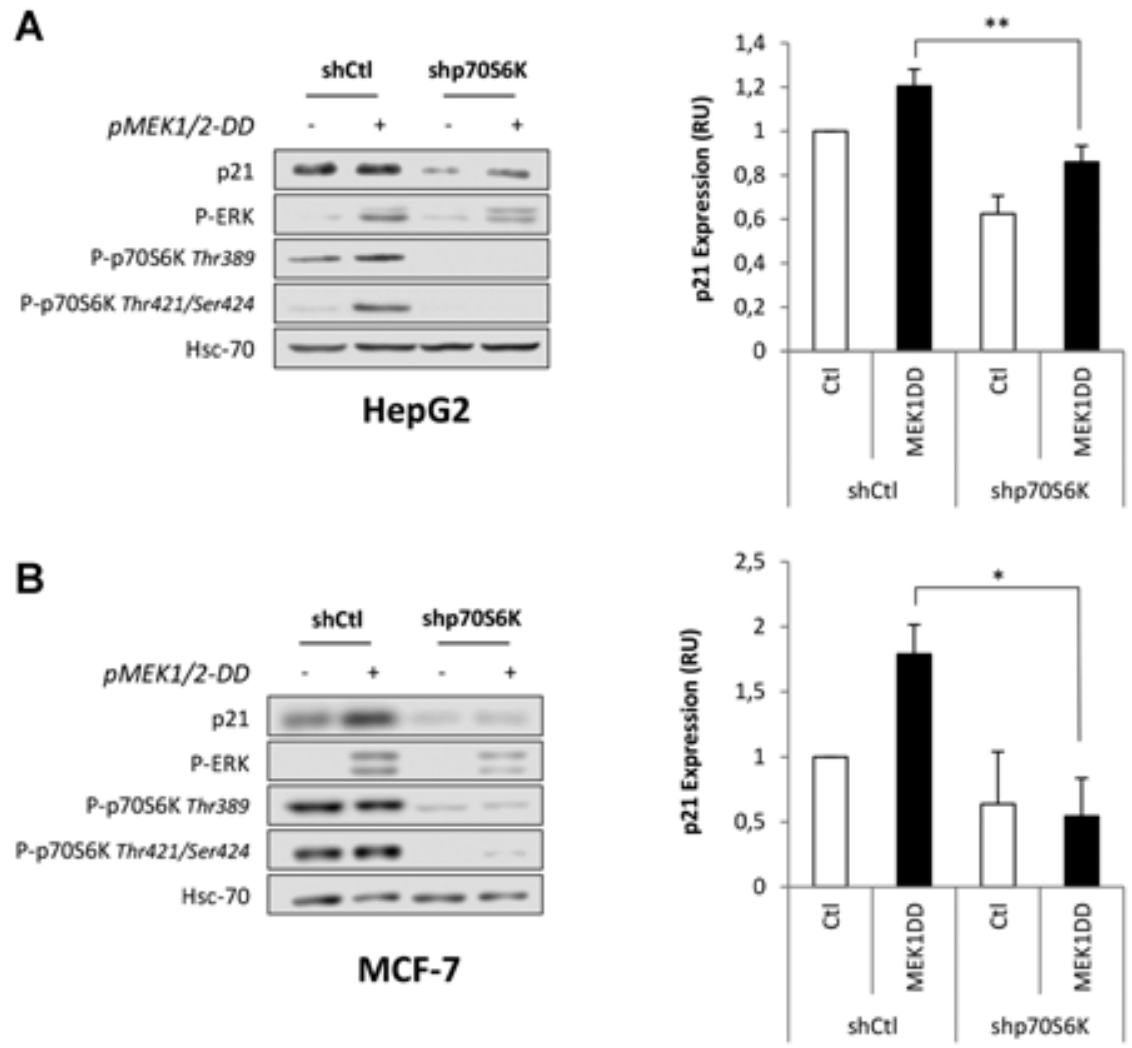